\title{
CRIMINOLOGIA
}

\section{La Criminología en la Unipersidad de Roma}

\author{
Por el Dr. EDUARDO MIMBELA.
}

Catedrático de Criminologia de la Univezsidad Nacional Mayor de San Marcos

El Instituto de Criminología de la Universidad de Roma funciona como anexo de la Escuela de Perfeccionamiento de Derecho Penal que fundara en 1911 Enrico Ferri, y que en el año de 1950 por iniciativa del entonces su Director, Prof. Grispigni, se acogió la idea de dársele también el nombre de Instituto de Criminoiogía, a la antedicha Escuela.

Es este uno de los motivos por los cuales los programas de enseñanza tienen carácter esencialmente mixto, encontrándose dentro de su curriculum grupos de materias jurídicas, biológicas y sociológicas. Las disciplinas estrictamente criminológicas se hallan inmerzas dentro de los grupos biológico y sociológico, formando ellas una constelación de ciencias criminológicas primordiales.

En su desenvolvimiento se establece que el Instituto funciona como dependencia de la Facultad de Derecho de la Universidad de Roma, teniendo su sede, dentro de esta Facultad, pero, conservando cierta autonomía en lo relativo a su propia organización y funcionamiento. Señálase, asimismo, el carắcter público del Instituto.

L $\alpha$ dirección está confiada al Profesor Ordinario de Derecho Criminal, siéndolo actualmente, Alfredo de Marsico. Los profesores son reclutada entre las personalidades que cultivan la especialidad.

En lo referente al ingreso, organización, método y programas de enseñanza, se estipula, que el Instituto podrá recibir a postulantes que poseen diplomas o licencias en Derecho, Economía, Ciencias Políticas y Sociales, así como a los graduados en Medicina y Cirugía, no importando la Universidad de procedencia, pudiendo ser ésta, nacional o extranjera. So reglamenta, asimismo, la admisión de licenciados en otras facultades universitarias, condicionando el ingreso de tales candidatos a un examen de Derecho y Procedimiento Penal.

En lo referente a la organización de la enseñanza, ésta se ha estructurado de manera tal que los estudiantes obtienen una formación teórica Y práctica, confiándose la explicación de ciertas materias a Institutos especializados de la Universidad, entre los que se enumera, el Instituto de 
Psicología, el de Antropología Criminal y el de Medicina Legal entre otros.

La duración de los estudios es de dos años, pudiendo el Consejo Directivo del Instituto, en casos especiales, reducir este lapso a un año, siempre y cuando se trate de alumnos con notorio aprovechamiento $\mathrm{Y}$ asidua concurrencia

Al término del curso, reglamentariamente, se entregará un diploma a los alumnos que hayan pasado con éxito los exámenes en cada una de las materias señaladas.

Por otro lado, la organización pedagógica del Instituto, ha dividido las disciplinas, allí explicadas, en tres grupos de materias a saber: Grupo Jurídico, Grupo Biológico y Grupo Sociológico, comprendiendo cada uno de ellos, los cursos siguientes: Grupo Jurídico: Ejercitación Científica $Y$ Práctica del Derecho Penal (Prof. De Marsico); Política Criminal (Prof. Do Marsico); Ejercitación Científica y Práctica del Derecho Procesal Penal (Prof. Janitti Piromalio); Derecho Penitenciario (Prof. Velotti); y Derecho de Policía (Prot Piacenza).

El Grupo Biológico: Antropo'ogía Criminal (Profesores: $\mathrm{Di}$ Tullio y Lombardi); Psicología Aplicada y Judicial (Profesores: Ponzo y Canastrelii); Psicología Criminal (Prof. Bontiglio); Medicina Legal Aplicada al Derecho Penal Prof. Gerin); y Técnica de Psicodiagnóstico en Criminología (Profesores: Ferracuti y De Grada).

El Grupo Sociológico comprende: Sociologia Criminal (Profs. Nicétoro y Morgantini); Técnica de la Instrucción Judicial (Prof. Sorrentino); Técnica y Medicina Penitenciaria (Dr. Licioni): todo lo cual, hace que el "pensum" del Instituto se cumpla en 14 materias o cursos.

Capítulo aparte, nos merece lo relativo a los métodos de enseñanza. La forma magistral y teorética, así como la enseñanza clínica, revisten cada una de ellas especiales perfiles de utilidad e importancia.

En Italia, especialmente en Roma, la enseñanza de la Criminología es impartida principalmente, en su aspecto o método clínico. De allí quø on la Escuela de Antropología Criminal de Roma, que dirige el Prof. Di Tullio, haya florecido la dirección de Criminología Clínica. Este tipo de onseñanza, se cumple, realizando estudios de casos particulares dentro de las diversas categorías de delincuentes con el fin de fortalecer un diagnóstico de la personalidad delictiva concreta, procediendo así como la afirma el Prof. Benigno Di Tullio a una evaluación de la génesis $y$ dinámica de los singulares fenómenos delictivos, propendiendo a señalar un tratamiento adecuado, sea. éste médico, psicológico o social-educativo pero, siempre, con criterios de clara singularidad.

Es de señalar que, en Italia, el desarrollo del método o enseñanza clínica de la Criminología ha sido facilitado por la existencia de centros criminológicos dentro de los más importantes establecimientos penitenciarios del país. A estos centros criminológicos, se les denomina Momicomios Judictales que, como el de Rebibbia en las afueras de Roma, significan fuentes valiosas de información científica. Tales creaciones se deben a la feliz iniciativa que tomara, en el año 1950, la Ádministración Penitenciaria Italiana. 
Por otro lado, la enseñanza se completa con trabajos prácticos $Y$ visitas a institutos especializados y establecimientos carcelarios. Asimismo, el Instituto cuenta con una Biblioteca rica en obras particularmente importantes en el dominio de la criminología, la misma que está a disposición de los alumnos.

Ahora bien, en lo referente a los programas de enseñanza y teniendo en cuenta la finalidad del presente artículo, sólo nos vamos a referir a las disciplinas criminológicas fundamentales. Ellas son: Antropología Criminal, Psicología y Psicopatología Criminales, Sociología Criminal y Penología.

Si tuviéramos que definir en dos palabras el pensamiento vivo de los profescres de Antropología Criminal de Roma y por tanto su contenido programático, diríamos, que es la búsqueda incesante del "antropologismo diferencial criminal", pensamiento vivo, que está nutrido por ese viejo numen que representa la primigenia idea de Lombroso.

No es hipérbole afirmar el sentido neo-lombrosiano que el profesor de Roma, Benigno Di Tullio, imparte a sus lecciones y a las interpretaciones clínicas, que realiza en el examen de las personalidades delictivas en el Manicomio Judicial de Rebbibia. Si bien es cierto, que, actualmente, no se habla del "patologismo criminal" de la vieja escuela, en cambio, hoy se investiga y hasta se "encuentran" los caracteres de constituciones predispuestas al delito, tal el caso, de la teoría de "la costiturione delinquenzíale" de Di Tullio $\mathrm{y}$ "la monogenesis diencefálica del delito" de Nicola Pende.

Así las cosas, la lógica consecuencia de tal postura se refleja en el programa del curso, donde se acusa una exagerada y desmedida influencia, no muy científica, de términos y conocimientos médicos dentro del área de la estricta Criminología. Existe la impresión, en quien esto escribe, que los criminólogos romanos quisieran reducir toda la Criminología a postulados no relievantes de la Somatología y Fisiología Criminales. Los criterios psicológicos y sociales, considerados independientemente, casi no se enumeran. La concepción psico-social de la conducta delictiva de proyecciones serias y reales se ha preterido. La.teoría de la "exteriorización del ambiente" de Nicéforo, tan útil en Criminología, sólo conserva, dentro del programa de Antropología Criminal, valor de referencia y siempre relativisóndola con los criterios antropológicos de los que está colmada $Y$ vastamente imbuída la Criminología en la Universidad de Roma.

E Programa, pues, considera los capítulos más tradicionales de la Antropología Criminal, los mismos que van, desde las causas biológicas de la conducta criminal hasta la profilaxis y terapia de la criminalidad, transitando, lógico es, por los problemas relativos a la herencia criminal, los procesos tóxicos, enfermedades mentales, cuestiones de bio-tipología $Y$ otros. La taxonomía delictiva así como un apéndice sobre generalidades penitenciarias y de Política Criminal, cierran el curso.

Ahora, en lo referente a la Psicología Criminal, cabe señalar que en la Universidad de Roma no existe un curso independiente de esta disciplina. Ella, se encuentra confundida con la Psicopatología Criminal. En Italia la dirección psicologista se daba hasta hace poco por la presencia de Agosti- 
no Gemelli - Rector de la Universidad Católica de Milón, fallecido en 1959quien, representaba la corriente más moderna del pensamiento criminológico italiano. Gemelli reconocía los méritos de la escuela antropológica, pero, consideraba que Lombroso y sus seguidores a la postre hicieron del criminal una figura tan abstracta como imposible. De este error también se han cubierto las modernas concepciones antropologistas del delito. Según Gemelli la reconstrucción de la conducta delictiva se hará teniendo en consideración a la Biología, a la Psicología y a la Sociología. Y será, a fin de cuentas, la Psicología la que nos llevará a determinar la mecánica del acto delictivo. (Ver: "La Personalitá del Delinquente nei suoi fondamenti biegisi e psicologici").

El Programa de la Psicopatología Criminal comprende, pues, los aspectos psicológicos y psiquiátricos de la conducta delictual, así como los métodos que han de emplearse para los exámenes de esos territorios.

Dentro del punto de vista psicológico, el Programa parte de la hipó. tegis según la cual, para afrontar el problema de la criminalidad y más particularmente el origen de sus causas y de su dinámica, es siempre necesario apoyarse sobre el conocimiento de la personalidad humana. La enseñanza tiende a presentar las personalidades que, alejándose estadísticamente de la media, se distinguen por un defecto de equilibrio entre las diversas capas que la componen $\mathrm{y}$, particularmente, entre el psiquismo inferior $\mathrm{Y}$ superior, entre el sentimiento e inteligencia, entre impulso y voluntad. Esta parte se cierra con el estudio de las diversas categorías de personalidades delictivas.

En cuanto al punto de vista psiquiátrico, se consideran en este paraje las principales alteraciones mentales que se presentan en el área delincuencial y los que pueden también ejercer influencia en las valoraciones de estímulos del mundo circundante en su relación con la mentalidad delictiva.

Entre las estudiadas encontramos: la locura moral, las' psicosis tóxicas, la epilepsia, el histerismo, las psicosis neuro-psicasténicas, la es. quizofrenia, la manía melancólica, la paranoia, la demencia senil y otras.

$E_{S}$ de notar que el curso se concluye con un apéndoce que expone las nociones fundamentales de Psicología Judicial. Se encaran en este aspecto el estudio psicológico de todas las personas que participan en el proceso penal: desde el inculpado hasta la parte civil desde los testigos hasta el Juez.

Continuando; el curso de Sociología Criminal, que enseñara el ilustre Profesor Altredo Nicéforo, en cuanto a su Programa, abarca los diferentes elementos del medio que comprometen el desarrollo de la criminalidad. Esta disciplina considera notablemente el medio natural geofísico, las condiciones de higiene y medio educativo.

Así, ella estudia la importancia que reviste desde el punto de vista del desarrollo de la criminalidad, el sexo, la edad, el clima, la naturaleza, del terreno, las alteraciones del día y la noche, las estaciones, los cambios de temperatura, la producción agrícola. Ella examina, igualmente, la influencia ejercida por la conducta humana y la criminalidad por el conjunto de condiciones de higiene en las cuales el individuo vive $y$ se desarrolla después de su nacimiento, haciendo hincapié, especialmente, en el 
punto de vista de la habitación y la alimentación, considerando, pues, ampliamente la Antropología de las clases pobres.

El Programa del curso concluye, cuando se ingresa a estudiar los problemas relativos a las irregularidades del medio familiar, las relaciones entre los padres, su moral, los hábitos de los diversos miembros de la familia respecto al trabajo, el juego, el alcoholismo, la insuficiencia de la instrucción escolar, la elección y visita de camaradas, los malos hábitos contraídos; la aptitud respecto al trabajo y la dificultad de encontrarlo; la ociosidad; la influencia ejercida por la lectura y los espectáculos, etc. Conviene señalar que estos cursos utilizan en gran medida las estadísticas criminales.

El estudio de los Programas de enseñanza de disciplinas criminológicas fundamentales, se concluye, con el de Penología.

La Penología y el Derecho Penitenciorio revisten una singular im. portancia dentro del plan de estudio del Instituto de Criminología de Roma. Los sistemas y métodos penitenciarios y sus relaciones con criterios estrictamente penales, son ampliamente enunciados. Se tiene de manera proferente, la definición del delito y la clasificación de los delincuentes. Todos estos aspectos están profundamente conectados con los fundamentos de la política penitenciaria a seguir. Los lineamientos del Derecho Penitenciorio se exponen cuando se refieren, al repglamento carcelario, a la clasificación y organización de establecimientos penales, a la clasificación de detenidos y a la observación y métodos de tratamiento de los mismos. Con los medios de prevenir la delincuencia y la asistencia de los detenidos liberados, se concluye el curriculum del curso.

Finalizando, me referiré muy brevemente al curso de Criminología Clínica, que fuera dictado por primera vez en el año de 1957 en el Manicomio Judicial de Rebbibia.

La enseñanza de esta disciplina está integrada por la Antropología Criminal, siendo aquella, la fase más reciente de estos estudios. Se subraya, dentro de esta dirección criminológica, la necesidad de observar y tratar al delincuente tomando como base los exámenes siguientes: el médico, que comprenderá a su vez la diversidad de pruebas clínicas que son utilizadas para la investigación patológica general; e) examen psicológico: el examen psiquíátrico $\mathrm{Y}$. finalmente, un examen sociológico $\mathrm{y}$ el tratamiento consiguiente ocupan los otros aspectos de la Criminología Clínica. 